\title{
El Tratado de Versalles: la firma de una Paz Cartaginesa
}

\author{
Patricia Kreibohm ${ }^{1}$
}

La Gran Guerra, que se inició en julio de 1914 tras el atentado de Sarajevo, finalizó el 11 de Noviembre de 1918 con un Armisticio entre los comandantes del Bloque Aliado y los representantes alemanes. Ese día, el primer ministro británico - David Lloyd George - señaló:

"Espero que podamos decir que, esta decisiva mañana, ha llegado el fin de todas las guerras."

La contienda había durado 4 años y 4 meses; un infierno de horror y destrucción que se había apoderado de la mayor parte de Europa. Cuando terminó, ya nada sería igual. Desde entonces, transformaciones decisivas afectaron la vida y la conciencia de los pueblos involucrados y así, se inició el declive de la hegemonía de Europa.

Tal vez lo más llamativo de esta contienda, no fue que estallara, sino las proporciones destructivas que adquirió; su inesperada duración, la dureza de la vida en el frente, las cuantiosas bajas, el sufrimiento de la población civil y la desmoralización colectiva; en definitiva, un conjunto de factores que habrían de marcar a toda una generación. Cuando empezó, muchos pensaron que iba a ser un conflicto limitado, sin embargo, una vez que se puso en marcha la maquinaria bélica, se tornó cada vez más difícil detenerla; sobre todo por la acumulación de las pérdidas y la desnaturalización de los objetivos que la habían desencadenado.

Desde nuestra perspectiva, esta contienda, fue una Guerra de Transición; es decir, un enfrentamiento en el que, si bien se mantuvieron constantes algunos elementos de las guerras anteriores, adquirió caracteres nuevos que se manifestaron durante su desarrollo. Dichos cambios, fueron sumamente significativos y fueron los que habrían de consolidarse, definitivamente, en la guerra que le siguió: la Segunda Guerra Mundial, a la que ya podemos identificar como una Guerra Total.

Analicemos, en primer lugar, algunas de estas modificaciones:

1. Aunque, indudablemente, esta guerra continuó siendo un acto político, destinada a dirimir un conflicto; su legitimidad como instrumento para la solución de controversias ya no resultó tan nítida. En efecto, los excesos, el encarnizamiento y la brutalidad

DOI: https://doi.org/10.24215/23142766e066

${ }^{1}$ Coordinadora Departamento de Historia. 
de las acciones, demostraron que la guerra se había convertido en una práctica atroz y despiadada, que había borrado los códigos y los límites que antaño la determinaron. $^{2}$

2. Si bien los Estados realizaron sus cálculos y evaluaron sus capacidades y sus riesgos mediante un análisis de costo-beneficio, en la Primera Guerra Mundial, ya empezaron a intervenir una serie de elementos "no racionales" que la desviaron de la simple ecuación inicial. En otras palabras, esta guerra ya no fue limitada: ni en el tiempo, ni en el espacio, ni en la inversión de recursos. Todas las potencias beligerantes creyeron que la guerra iba a durar sólo algunos meses, sin embargo, se extendió durante 4 años; afectó a toda Europa; tuvo consecuencias para potencias de todo el mundo y supuso que todos los beligerantes invirtieran toda su capacidad económica, industrial, tecnológica y moral en este combate.

3. Asimismo, en esta contienda empezó a desvanecerse la mística y la simbología de otros tiempos: de hecho, las acciones de combate ya no remitían de manera tan concreta a los valores nobles: la gloria, la valentía, la nobleza y sus objetivos parecían bastante ajenos a conceptos como los de virtud, razón y justicia.

4. Muy relacionado a lo anterior, la Gran Guerra se convirtió en un combate a muerte en el que la población civil fue, paulatinamente, sufriendo directamente la brutalidad de las acciones. De hecho, y de manera sistemática, los civiles se convirtieron en blancos militares, atacados deliberadamente para quebrar la moral de sus gobiernos.

5. En este marco, esta conflagración dejó de ser un enfrentamiento entre adversarios, para convertirse en una lucha entre enemigos. En efecto, tanto por la crueldad de los combates, como por los sufrimientos infringidos a la población civil, esta contienda marcó un punto de inflexión que ya no tendría retroceso.

6. Finalmente, en el marco de la Conferencia de Paz de Paris, se firmó el Tratado de Versalles con Alemania. Allí quedó bien claro que la paz ya no sería negociada; por el contrario, lo que se les impuso a los vencidos fue una Paz por Imperio - según la categoría de Raymond Aron - que Alemania fue forzada a firmar. ${ }^{3}$

Como sostiene Henry Kissinger, a diferencia de lo ocurrido en el Congreso de Viena, la Conferencia de Paz de Paris, no incluyó a las potencias vencidas. Por consiguiente, los meses de negociaciones - que se iniciaron en enero del 19 - generaron en los alemanes una gran incertidumbre que los condujo a concebir distintas ilusiones. La más importante era que la decisión final de los Aliados sería bastante benigna. Por ello, cuando se les comunicó el resultado final - en Junio de 1919 - los funcionarios alemanes se indignaron; se negaron a firmar el documento y renunciaron a sus cargos. De hecho, el conde Ulrich von Brockdorff$\underline{\text { Rantzau }}$, quien dirigía la delegación alemana, expresó en ese momento:

\footnotetext{
${ }^{2}$ Poco tiempo después, y como producto del azoramiento que había producido el conflicto, se firmó entre Inglaterra y Francia el Pacto Briand-Kellog, que establecía la ilegalidad de la guerra.

${ }^{3}$ En efecto, en el texto de la rendición, Alemania no pudo modificar ni una coma y además, las condiciones se le impusieron de manera humillante y ominosa.

Aron, Raymond. Op. Cit.
} 
"Alemania se niega a firmar este tratado...debido a las condiciones de paz que se le imponen y que implican la destrucción económica y el deshonor político y moral de Alemania y las generaciones presentes y futuras". 4

Los días siguientes estuvieron signados por las presiones de los vencedores. De hecho, el Comando de las Fuerzas Aliadas advirtió a los alemanes que, si no firmaban, los vencedores quedarían habilitados para "proceder sin ningún límite en las operaciones militares". Ante esta situación, se presentó la contrapropuesta de los derrotados que, básicamente, solicitaba tres puntos conretos: que sus minas carboníferas del Sarre no fueran ocupadas y usufructuadas por los aliados; que consideraban humillante la cesión completa de territorios a Bélgica y a Polonia y que advertían que, en esas condiciones, no podrían pagar las "reparaciones" que se les demandaba.

“Alemania está dispuesta a indemnizar daños, pero no puede hacerlo si no le dejan suficiente carbón para las industrias...Alemania, no está dispuesta a ceder territorios netamente alemanes y no tiene la intención de ofrecer resistencia, pero no dejará gobernar a los aliados".

La respuesta de los aliados, reproducida íntegramente por el diario La Gaceta de Tucumán, sostiene que:

"Esta guerra fue el mayor crimen consciente contra la humanidad y la libertad de los pueblos, y por parte de un pueblo, pretendiéndose civilizado...Por mucho tiempo, los gobiernos alemanes, fieles a la tradición prusiana, se esforzaron por obtener la hegemonía de Europa. Cuando todos los pueblos libres procuraban la prosperidad e influencia que reivindicaban legítimamente, quisieron dominar o tiranizar a Europa y esclavizarla como hacían de Alemania, inculcando a sus súbditos la doctrina de que la fuerza es el derecho y desarrollaron los armamentos bajo el pretexto falso de envidia de los vecinos...Así preparados, alentaron a un aliado esclavizado (tal el concepto del extinto Imperio de Austria-Hungría) a descargar contra Servia la guerra, siendo este país el control de los Balcanes. (...) Alemania es responsable del desencadenamiento de la guerra, es responsable de su conducta salvaje e inhumana y de sus gobiernos que violaron la neutralidad belga, de la que Alemania era garante...Con objeto de terror sistemático procedieron a ejecuciones e incendios deliberados, usaron los primeros gases tóxicos, bombardeos aéreos, tiros contra ciudades lejanas sin razón militar, y la campaña submarina, desafío de piratas al derecho internacional, causando numerosas muertes inocentes, o lo que es peor aún, poniéndolos a merced de las tripulaciones de los submarinos...Esclavizaron de manera salvaje y brutal y deportaron a millares de hombres y mujeres...Infringieron a los prisioneros tratos bárbaros que parecían increíbles a los menos civilizados. Alemania tendrá la justicia que reclama, pero la justicia debe hacerse por todos los muertos, heridos, enfermos y enlutados, a fin de que Europa se vea en libertad del despotismo prusiano. La justicia impone restituciones y la protección momentánea hacia Alemania, industrialmente intacta y hasta

\footnotetext{
${ }^{4}$ Titulares del diario La Gaceta de Tucumán. 29 de junio de 1919.
} 
fortificada por sus robos, advirtieron...Alemania, que sólo hizo daño, debe sólo sufrir consecuencias".

Los Estados invitados a la Conferencia fueron 27 y, desde su inicio, fue claro que más que un foro para los pueblos, éste sería un nuevo campo de batalla; esta vez, diplomático. El Consejo Supremo - compuesto por los jefes de gobierno de La Gran Bretaña, Francia, Italia y Estados Unidos - era el de más alto rango. Estaba además, el Consejo de los Cinco; el Consejo de los Diez y luego venía una serie casi interminable de comisiones y secciones específicas. En total, al final de la Conferencia, se contabilizaron 58. Muchos estaban dedicados a las cuestiones territoriales pero también hubo otros que se avocaron a asuntos tales como: la culpabilidad de la guerra; las reparaciones; los puertos, las vías acuáticas y la flota mercante; la mano de obra; los recursos que deberían ser entregados, etcétera. En total, los delegados a la conferencia asistieron a 1646 reuniones.

Por otra parte, como no se había establecido una agenda previa, los delegados desconocían cómo y cuándo se tratarían los asuntos. De hecho, desde su inicio, las alternativas de este acuerdo no sólo fueron complicadas y conflictivas, sino que los debates y las discusiones, se hicieron interminables; los asuntos secundarios oscurecían los objetivos centrales y hacían perder de vista una cuestión crucial: cuál iba a ser el papel de Alemania en la Europa de la post-guerra.

"En teoría, los principios norteamericanos de seguridad colectiva y de autodeterminación habían de desempeñar ese papel. En la práctica, la auténtica cuestión de la Conferencia (que resultó irresoluble) serían las diferencias entre el concepto norteamericano de un Orden Internacional y el de los europeos, en particular el de los franceses. Wilson rechazó la idea de que los conflictos internacionales tuviesen causas estructurales. Considerando natural la armonía, Wilson se esforzó por crear unas instituciones que disiparan para siempre esa ilusión del choque de intereses y que permitieran reformar el concepto subyacente de una Comunidad Mundial...

Francia, teatro de muchas de las guerras europeas y partícipe de muchas otras, no se dejaría persuadir de que el choque de intereses nacionales era ilusorio, o de que existía alguna nebulosa armonía subyacente, hasta entonces oculta a la Humanidad... Aspiraba a tener garantías tangibles a su seguridad y dejaba a otros el adoctrinamiento moral de la Humanidad. Pero esas garantías implicaban, o bien un debilitamiento de Alemania, o bien la seguridad de que, en caso de otra guerra, ciertos países, especialmente EEUU y Gran Bretaña, estarían del lado de Francia.... Como los EEUU se oponían al desmembramiento de Alemania y la Seguridad Colectiva, resultaba demasiado nebulosa para Francia, la única solución a su problema era un compromiso norteamericano y británico de defenderla. Y eso era justo lo que ambos países anglosajones se mostraban en extremo renuentes a otorgar." ${ }^{5}$ ebates

De todos estos debates surgió, finalmente, el Tratado de Versalles; un tratado demasiado punitivo para ser conciliador y demasiado benigno para impedir que Alemania se recuperara. De hecho, este tema también se tornó complicado porque durante el proceso,

\footnotetext{
${ }^{5}$ Kissinger, Henry. La diplomacia. FCE. México 1994. P. 229
} 
muchos empezaron a comprender que una Alemania económicamente postrada, podría provocar una crisis mundial que terminaría afectando a sus propias sociedades. Sin embargo, también sabían que a las poblaciones victoriosas no les importaba la opinión de los economistas. Lo que finalmente se aceptó fue incluir una cláusula por la cual Alemania pagaría las pensiones de las víctimas de guerra y una compensación a sus familias. Semejante cláusula era inaudita: nunca un tratado de paz europeo había contenido cosa semejante.

Como se evaluaría más adelante, las negociaciones no sirvieron para consolidar la paz y recuperar la convivencia colectiva europea. En este sentido, son muchos los historiadores que coinciden en sostener que la mala resolución de la Paz de Versalles, no sólo afectó a los vencidos, sino que tampoco satisfizo a muchos de los vencedores; en definitiva, el documento sólo sirvió para incrementar los temores, las desconfianzas y los resentimientos.

En efecto, de acuerdo al análisis de algunos autores, estas condiciones hipotecaron el Nuevo Orden Internacional pues sólo pudieron crear un compromiso frágil, situado entre el utopismo norteamericano y la paranoia europea.

Con respecto a la disolución de los grandes imperios - el Austro-Húngaro y el Otomano - en la Conferencia se decidió crear una serie de nuevos Estados (Hungría, Checoslovaquia, YugosIvaia, Rumania) y un sistema de Mandatos, que estaría bajo la supervisión de la Sociedad de las Naciones. Este nuevo modelo de control, que sólo iba a mantenerse por la fuerza, era precario, inestable y, sobre todo, notablemente injusto.

Cuando ya era demasiado tarde, Lloyd George comprendió el dilema en el que estaban los Aliados. En un memorándum a Wilson, del 25 de marzo de 1919, escribió:

“No puedo concebir mayor causa para una guerra futura que la del pueblo alemán - que ciertamente ha demostrado ser una de las razas más robustas y poderosas del mundo - que se encuentra rodeado por un número de Estados pequeños, cada uno de los cuales contiene grandes masas de alemanes que van a clamar por reunirse con su patria"

Para los alemanes, este Tratado fue un Diktat impuesto por la fuerza; un Tratado que no era tal pues no se había permitido ningún mecanismo de consulta o de participación. Pero tal vez, lo que más pesaba a los vencidos, era la cláusula de culpabilidad. En efecto, el núcleo conceptual de Versalles se concentra en el artículo 231, que adjudicaba a Alemania y sus aliados toda la responsabilidad moral y material de haber causado la guerra y de todos sus costos y perjuicios. Dicho artículo, que más adelante fue calificada como: la Mentira de la Culpa de Guerra - establecía que:

"Se declara a Alemania como culpable de todos los daños y las pérdidas infringidos a los gobiernos Aliados y asociados. Alemania se compromete, por ello, a reparar, como establece el anexo 1, daños causados a civiles por los actos de guerra, por actos de crueldad, daños que atenten contra la capacidad de trabajo, daños relativos a los bienes, etc."

Desde luego, Alemania tenía una gran responsabilidad, pero ¿era justo adjudicarle toda la culpa? 
El 21 de junio del 19, se conoció la renuncia en pleno, del gabinete alemán. El 24, la asamblea nacional alemana decidió, por 237 votos contra 138, firmar el Tratado de paz, que se rubricó un 28 de junio. Ese día, nada terminó. ${ }^{6}$

El documento contiene quince partes y 440 artículos; un monumento inspirado por el ceremonial de las reparaciones y la revancha - como sostiene Pasquale Villani - que sólo fue efectivo para alentar las rivalidades y las desconfianzas nacionales. ${ }^{7}$ De hecho, mientras Estados Unidos decidió no intervenir en la cuestión, el Reino Unido buscaba un equilibrio, debido a que su gobierno advirtió que, con las condiciones establecidas, Alemania no podría recuperarse y, por lo tanto, sería incapaz de afrontar las exigencias. Francia, por su parte, se mostraba inconmovible; identificaba a Alemania como la responsable de la guerra y exigía que pagara absolutamente todos los costos que se le impusieran.

Analicemos a continuación, algunas de las sanciones que se le impusieron a Alemania; sanciones que, poco tiempo después, habrían de ser usadas políticamente por el régimen nazi para conducir al país y al mundo, a un nuevo infierno; un infierno mucho más profundo y terrorífico que el anterior.

En primer término, se destacan las prohibiciones referidas a las capacidades militares: entrega de todo el material militar y de la flota de guerra; ocupación de la orilla izquierda del Rin y desmilitarización de Renania; reducción del ejército a 100000 hombres y 4000 oficiales, sin artillería pesada, submarinos ni aviación. Prohibición de fabricar material de guerra. Disolución del Estado Mayor del Ejército y supresión del servicio militar obligatorio en Alemania.

En cuanto a la cuestión territorial, Alemania perdió $13 \%$ de su territorio: de tener $540766 \mathrm{~km}^{2}$ pasó a tener $468787 \mathrm{~km}^{2}$ y fue obligada a ceder todo su imperio colonial, que fue repartido entre las naciones vencedoras, principalmente entre el Reino Unido y Francia.

Las partes Novena y Décima del Tratado, establecían la creación de una Comisión de Reparaciones de Guerra, la cual fijó los montos y los recursos financieros y económicos que debían pagar los alemanes. Entre ellos se destaca: una cantidad inusitada de marcos en oro; importantes ventajas y privilegios económicos y comerciales para las Naciones vencedoras; la entrega de la mitad de la producción química y farmacéutica, carbón, cabezas de ganado, producción agropecuaria y todos los barcos de la flota mercante.

Finalmente, y por iniciativa del presidente Wilson, el Tratado estableció la creación de un organismo específico, cuya misión sería garantizar la paz y la seguridad a nivel internacional. La Sociedad de las Naciones, nació en 1920, pero a Alemania se le prohibió el ingreso.

Así se cerró este Tratado que puso fin a la guerra y que no fue, en realidad, un Acuerdo de Paz. Como sostuvo John Keynnes, que participó en las negociaciones, esta fue una paz cartaqinesa; es decir una imposición brutal y humillante a un enemigo que había sido derrotado en un conflicto bélico. ${ }^{8}$

\footnotetext{
${ }^{6}$ Aurane, Alvaro. El epílogo de la Gran Guerra Europea. Anuario del Diario La Gaceta 2014. S. M. de Tucumán.

${ }^{7}$ Villani, Pasquale. La edad contemporánea: 1914 - 1945. Ariel Historia. Barcelona. 1997 P. 48

${ }^{8}$ La expresión deriva de la paz que impuso Roma a Cartago tras la derrota de la potencia norteafricana en la Segunda Guerra Púnica .
} 
“Esta paz cartaginesa no era ni buena, ni posible ni práctica...y parece más bien un ataque a la piedad $\mathrm{v}$ al buen sentido que una vía para solucionar definitivamente los conflictos entre las partes." 9

A partir de entonces, se inició lo que conocemos como el Período de Entreguerras, una etapa conflictiva, inestable y sumamente tensa, que habría de desembocar en una nueva guerra.

Atrás quedó la hegemonía del Concierto Europeo, la Belle Époque y el mundo de las ilusiones burguesas; el Romanticismo decimonónico y la grandeza de las dinastías. A partir de los años 20, cambió la mentalidad colectiva, surgieron las Vanguardias que transformaron el arte y la música; la producción industrial y las sociedades, empezaron a hacerse masivas y el rol de la mujer también se transformó, lo cual modificó la vida familiar, laboral y social. Pocos años más tarde, la Gran Crisis y la Depresión de 1929/30, hicieron evidente que uno de los elementos fundamentales de esta catástrofe, había sido la cadena de endeudamiento y las deficiencias de la paz europea.

${ }^{9}$ Crouzet, Maurice. Historia general de las civilizaciones. Volumen VII: La época contemporánea. Destino. Barcelona. P. 40 